[0212-7199 (2008) 25: 1; pp 31-32] ANALES DE MEDICINA INTERNA Copyright (C) 2008 ARAN EDICIONES, S.L.

AN MED INTERNA (Madrid) Vol. 25, N. ${ }^{\circ} 1$, pp. 31-32, 200

\title{
Infarto agudo de miocardio en gestante a término de 39 semanas tratado con fibrinolisis
}

\author{
J. A. CAMACHO PULIDO, J. M. JIMÉNEZ SÁNCHEZ, A. MONTIJANO VIZCAÍNO, \\ B. JURADO LARA, A. DE MOLINA ORTEGA
}

Unidad de Medicina Intensiva. Hospital San Agustín. Linares, Jaén

\begin{abstract}
ACUTE MIOCARDIAL INFARCTION IN PREGNANCY OF 39 WEEK TREATED WITH FIBRINOLYSIS
\end{abstract}

\begin{abstract}
RESUMEN
Exponemos el caso de una paciente de 39 años de edad con gestación a término de 39 semanas que sufre un cuadro de infarto agudo de miocardio con criterios clínicos y electrocardiográficos y que fue tratada con fibrinolisis sistémica. Posteriormente fue trasladada al servicio de hemodinámica del Hospital de referencia donde se realizó cateterismo confirmando la lesión coronaria. A las 24 horas de éste episodio dio a luz un recién nacido a término sin complicaciones mediante parto vaginal.
\end{abstract}

PALABRAS CLAVE: Infarto agudo miocardio. Embarazo. Fibrinolisis.

\begin{abstract}
We report a 39 years old woman at ehr $39^{\text {th }}$ week of pregancy who presented acute miocardial infarction with clinics and electrocardiography criteria and was trated with systemic fibrynolisis. After this was traslated to hemodynamic service of referency hospital were was done cateterism thas confirmed the coronary lession. 24 hours after she had an newborn without secuels.
\end{abstract}

KEY WORDS: Acute miocardial infarction. Pregnancy. Fibrinolysis.

Camacho Pulido JA, Jiménez Sánchez JM, Montijano Vizcaíno A, Jurado Lara B, de Molina Ortega A. Infarto agudo de miocardio en gestante a término de 39 semanas tratado con fibrinólisis. An Med Interna (Madrid) 2008; 25: 31-32.

\section{INTRODUCCIÓN}

Presentamos el caso de una paciente en que la cardiopatía isquémica se presentó en los últimos momentos de la gestación, amenazando tanto a la madre como al feto. En estos casos se plantean siempre las posibilidades terapéuticas según los recursos disponibles y la urgencia del caso. En el nuestro al no disponer de laboratorio de hemodinámica el retraso en el tratamiento podía ser fatal. Al no existir literatura descrita en esta situación creemos interesante darlo a conocer.

\section{CASO APORTADO}

Se trata de una mujer de 39 años de edad que acude al servicio de Urgencias por un cuadro de dolor toracico con carácter opresivo y que se irradia a ambos brazos, acompañado de intenso cortejo vegetativo en forma de mareo, nauseas y vómitos.

Refiere un embarazo a término de 39 semanas de gestación.

Como antecedentes personales es fumadora, tiene hipercolesterolemia sin tratamiento y tiene antecedentes de un hermano con infarto de miocardio y madre con angina estable. No toma medicación habi- tual. A su llegada a Urgencias se detectan alteraciones en el electrocardiograma compatibles con infarto agudo de miocardio por lo que ingresa en UCI.

Exploración al ingreso: T. arterial: $85 / 60 \mathrm{mmHg}$, F. cardíaca: 70 lpm. $\mathrm{T}^{\mathrm{a}}: 36,5^{\circ} \mathrm{C}$. Consciente y orientada, sensación de enfermedad grave. Presenta dolor precordial.

Exploración neurológica normal. Índice APACHE-II: 8 puntos. No disnea ni taquipnea.

La auscultación cardiopulmonar es normal sin soplos ni roce pericárdico y con ausencia de crepitantes ni sibilantes a nivel pulmonar. El abdomen es propio de una gestante a término de 39 semanas y en miembros inferiores presenta edemas moderados con fovea.

El servicio de Ginecología comprueba el buen estado fetal al ingreso de la enferma.

Pruebas complementarias: Bioquímica tras una hora del comienzo del dolor: glucosa: $11 \mathrm{mg} / \mathrm{dl}$, urea: $13 \mathrm{mg} / \mathrm{dl}$, creatinina: 0,60 $\mathrm{mg} / \mathrm{dl}$, Na: $137 \mathrm{mmol} / \mathrm{l}, \mathrm{K}: 3,8 \mathrm{mmol} / \mathrm{l}$, PCR: 1,10 mg/dl, GOT: 17 UI/1, GPT: $17 \mathrm{UI} / 1, \mathrm{LDH}: 176 \mathrm{UI} / 1$, amilasa: $57 \mathrm{UI} / 1$, mioglobina: $18,50 \mathrm{ng} / \mathrm{ml}$ (normal hasta $0,3 \mathrm{ng} / \mathrm{ml}$ ), CPK- MB: 3,5 ng/ml (normal hasta $7,2 \mathrm{ng} / \mathrm{ml})$.

Electrocardiograma: ritmo sinsual. Sin alteraciones de la conducción auriculo-ventricular. Elevación del segmento ST de $2 \mathrm{~mm}$ en II, III y aVF con cambios especulares en I y aVL (Fig. 1).

Trabajo aceptado: 31 de agosto de 2007 


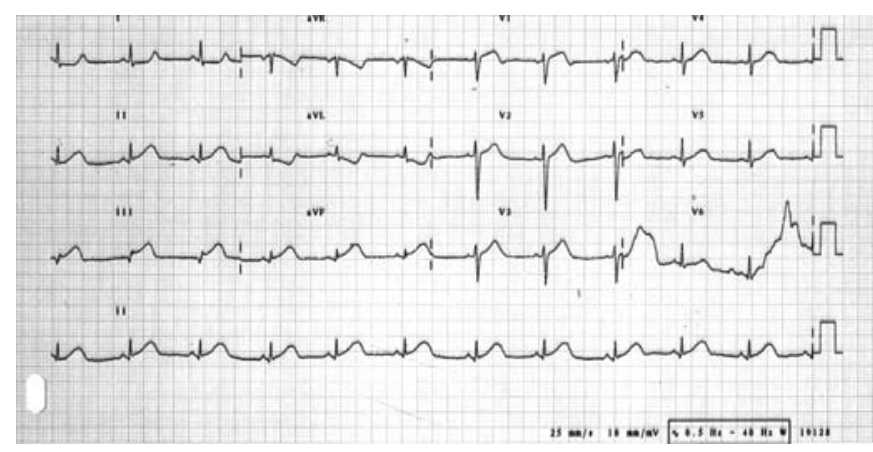

Fig. 1. Resonancia nuclear magnética con contraste (T1: sangre negra): masa con realce que se extiende entre las desembocaduras de la vena cava superior e inferior, ocupando la porción posterior de la cavidad auricular.

Hemograma: leucocitos: $10.240 \mathrm{~mm}^{3}$, hematíes: $4,01 \mathrm{mill} / \mathrm{mm}^{3}$, hemoglobina: $9,9 \mathrm{~g} / \mathrm{dl}$, hematocrito: $29,8 \%$, plaquetas: $430.000 \mathrm{~mm}^{3}$, neutrófilos: $68,4 \%$, linfocitos: $24,8 \%$.

Gasometría venosa: $\mathrm{pH}: 7,33, \mathrm{pCO}_{2}: 28, \mathrm{pO}_{2}: 53, \mathrm{BE}:-10,5$, CO3H-: 15,5 .

Estudio de coagulación: Alterado por fibrinolisis sistémica.

Ecocardiografía transtorácica: Pequeño derrame pericárdico posterior menor a $5 \mathrm{~mm}$. Resto de la exploración sin alteraciones.

En la evolución la enferma presenta hipotensión que necesitó de la administración de volumen para recuperarla. Dado el cuadro clínico de IAM en fase hiperaguda se decidió trombolisis sistémica con tenecteplase (TNK) según protocolo. Se adminsitraron $30 \mathrm{mg}$ de enoxaparina iv y 7000 UI de tenecteplase en bolo. De igual forma se inició tratamiento con oxígeno, ácido acetilsalicílico $200 \mathrm{mg}$, clopidrogel $300 \mathrm{mg}$ y solinitrina intravenosa tras recuperar la tensión arterial. En las siguientes horas la paciente queda asintomática sin dolor y hemodinamicamente estable.

Se aprecian extrasístoles ventriculares frecuentes. Tras estabilización se decide traslado al hospital de referencia para realización de cateterismo coronario. Se realizó dicho tratamiento evidenciándose lesión en la arteria coronaria derecha que se trata con stent.

A las 24 horas de éste cuadro la paciente dio a luz un recién nacido a término por parto vaginal sin secuelas materno-fetales.

\section{DISCUSIÓN}

El infarto agudo de miocardio raramente aparece en mujeres en edad fertil y se ha estimado que ocurre en una de cada 10.000 mujeres embarazadas (1). En estos casos, la arterioesclerosis coronaria suele ser la causa más frecuente.Otras causas incluyen tromboembolismo, disección coronaria espontánea y vasoespasmo arterial coronario severo (2). El tratamiento trombolítico es la primera linea de tratamiento actual en ésta patología aunque con frecuencia el embarazo ha sido una contraindicación a dicho tratamiento. Dicha contraindicación es puramente teórica y basada en protocolos previos. Hay algunos casos descritos de tratamiento trombolítico exitoso en el embarazo (3). En el contexto de un IAM con embarazo posiblemente la mejor estrategia sería un tratamiento con angioplastia primaria pero esto no siempre está disponible como es nuestro caso de forma urgente. En la revisión de Leonhart se describen 20 casos de trombolisis durante el embarazo con rt-PA en la literatura con indicaciones como accidente cerebrovascular, trombosis de válvulas cardíacas protésicas, embolismo pulmonar, trombosis venosa profunda y un IAM (4). Ninguno de los recién nacidos en ésta serie sufrió secuelas como en nuestro caso. El diagnóstico rápido y el tratamiento inmediato son fundamentales para disminuir la mortalidad materno- fetal en ésta entidad (5). Además la mortalidad meterna varía según el IAM se desarrolle antes del parto o en el puerperio. Si se produce durante el embarazo hay mayor mortalidad y complicaciones que si se produce tras el parto (17,7 frente al 14,2\%) (6). En algunas series se comprueba además que la mayoría de los casos de IAM en el embarazo se producen en el segundo y tercer trimestre del mismo posiblemente relacionados con el ambiente procoagulante en el organismo de la mujer gestante (7).

Finalmente creemos que aunque el gold standard es la angioplastia primaria aún hoy día ésta técnica no está disponible de urgencia siempre que se necesita por lo que el tratamiento trombolítico puede ser la única posibilidad de tratamiento de una gestante con IAM en fase aguda, mucho más cuando aparecen complicaciones hemodinámicas graves que no admiten demora en el tratamiento.

\section{Bibliografía}

1. Hankins GD, Wendal JrGD, Loveno K J, et al. Myocardial infarction during pregnancy; a review. Obstet Gynecol 1985; 65: 139-46.

2. Sullivan JM, Ramanathan KB. Management of medical problems in preganancy - severe cardiac disease. N Engl J Med 1985; 313.

3. Shumacher P, Belfort MA, Card RJ. Successful treatment of acute myocardial infarction during pregnancy with tissue plasminogen activator. Am J. Obstet Gynecol 1997; 176: 716-9.

4. Leonhart G, Gaul C, Niestch HH, Buerke M, Schleussner E. Thrombolytic therapy in pregnancy. J. Thromb Thrombolysis $2006 ; 21$ (3):
271-6.

5. Hartel D, Sorges E, Carlsson J, Romer V, Tebbe U. Myocardial infarction and thromboembolism during pregnancy. Herz, 2003; 28 (3): 17584.

6. Heidi E. Ladner MD, Beate Danielsen , Ph D. And William M. Gulbert, $\mathrm{MD}$. Acute myocardial infarction in pregnancy and the puerperium: A Population - based study. Obstet. Gynecol 2005; 105: 480-4.

7. Roth A, Elkayam U. Acute myocardial infarction associated with pregnancy. Ann Intern Med 1996; 125: 751-62. 